\title{
Synthesis and characterization of a novel Schiff-base/SBA-15 nanoadsorbent for removal of methylene blue from aqueous solutions
}

\author{
G. R. Bardajee $\cdot$ Z. Hooshyar $\cdot$ F. E. Shahidi
}

Received: 3 June 2014/Revised: 7 November 2014/Accepted: 7 December 2014/Published online: 23 December 2014

(C) Islamic Azad University (IAU) 2014

\begin{abstract}
A novel Schiff-base/SBA-15 nanoadsorbent was successfully synthesized by the reaction of salicylaldehyde and (3-aminopropyl) trimethoxysilane in methanol and subsequent grafting with SBA-15. The morphology and structures of the as-synthesized Schiff-base/SBA-15 nanoadsorbent were characterized by powder X-ray diffraction, transmission electron microscopy, Fourier transform infrared spectroscopy, thermo-gravimetric analysis, and $\mathrm{N}_{2}$ adsorption/desorption isotherms. The obtained Schiff-base/SBA-15 nanoadsorbent was used for the removal of methylene blue (MB) from aqueous solutions. The effects of various parameters such as temperature, concentration, $\mathrm{pH}$, and contact time were examined, and optimal experimental conditions were determined. The equilibrium isotherms were conducted using Freundlich and Langmuir models. The pseudo-first-order, pseudosecond-order, and intraparticle diffusion models were used to fit adsorption data in the kinetic studies. The thermodynamic parameters such as the standard enthalpy, standard entropy, and standard free energy were evaluated. The obtained results indicated that the Schiff-base/SBA-15 nanoadsorbent is an efficient adsorbent for removing MB.
\end{abstract}

Keywords Schiff-base - SBA-15 - Nanoadsorbent . Methylene blue $\cdot$ Kinetic model

\section{Introduction}

With industrialization, large varieties of dyes are discharged into the environment and make up the most

G. R. Bardajee $(\bowtie) \cdot$ Z. Hooshyar · F. E. Shahidi

Department of Chemistry, Payame Noor University, PO BOX 19395-3697, Tehran, Iran

e-mail: rezanejad@pnu.ac.ir significant environmental contaminants found in wastewater (Guo et al. 2014). Long-term exposure to those solvated dyes and consequently their effects on human health and natural ecosystems are critical issues. Methylene blue (MB) is the cationic dye that is most commonly used for coloring of cotton, wool, and silk (Suresh et al. 2014). MB can cause eye burns in humans and animals, methemoglobinemia, cyanosis, convulsions, tachycardia, dyspnea, irritation to the skin, and if ingested, can make irritation to the gastrointestinal tract, nausea, vomiting, and diarrhea (Ghaedi et al. 2014a, b, c Wang et al. 2014; Chala et al. 2014; Lin et al. 2014; Spires-Jones et al. 2014). The most efficient way for the elimination of MB from aqueous effluents is the adsorption process. To become an adsorbent for MB with best performance, a set of conditions must be met which include the occurrence of an open-pore structure and accessible adsorption sites; structurally stable adsorbent under adsorption; and good contact between the MB and the adsorption sites (Petzer et al. 2014; Liu et al. 2014; Ahmed and Theydan 2014; Chunhui et al. 2013; Ting et al. 2014).

Significant efforts have been done to build up new adsorbents for removing dyes from water and non-aqueous solvents (Adam et al. 2013). The use of hexagonally ordered mesoporous silica materials have attracted many researchers because of their unique properties such as wellordered structure, regular pore sizes, and high thermal stability (Karimi and Ghaedi 2014; Chang et al. 2013). Many researches show that silica-based structures have good biocompatibility, high lenience to many organic solvents (Messina and Schulz 2006; Rafatullah et al. 2010), and uncomplicated surface functionalization. Then, those materials with diverse chelating agents are increasingly utilized as adsorbents (Valle-Vigón et al. 2013; Suchithra et al. 2012). Among these materials, SBA-15 has been 
intensively studied (Cheraghali et al. 2013). SBA-15 materials have ordered mesoporous silica features with larger and tailored mesoporous pore diameters, which the pore sizes can be controlled from 3 to $20 \mathrm{~nm}$. They have also thicker walls in the region of $4 \mathrm{~nm}$ which let easier convenience of more species to the inner surface of the material and lead to fast chemical or physical processes (Bui and Choi 2009; Ghaedi et al. 2014a, b, c; Anbia and Amirmahmoodi 2011; Yan et al. 2013; Da'na and Sayari 2011). Furthermore, they can be modified with organic groups to tailor their properties and reach specific functions (Ghaedi et al. 2014a, b, c; Wang et al. 2013). Two ways are usually used for modification of SBA-15: co-condensation and post-grafting synthetic procedures. In the first method, the functional silane is added to a mixture of tetraethoxysilane and surfactant, with a concomitant formation of the final functionalized structure. In the second method, the ordered mesoporous skeleton is first obtained, and the desired silane is added to the suspension in a second step to result in the final functional solid (Tang et al. 2011; Hernández-Morales et al. 2012; Li et al. 2014). Recently, Bardajee et al. (2013) reported the use of SBA-15 containing a Schiff-base ligand as a catalyst for the synthesis of 2,3-disubstituted quinoxalines and pyridopyrazine derivatives.

Schiff-base derivatives belong to the compounds with nitrogen-carbon double bond, which can exhibit various properties to be applied to such fields as organic synthesis, catalyst, liquid crystal, and bioinorganic chemistry (Anacona et al. 2014). Schiff-base can be introduced in the inorganic/organic hybrid materials' systems through the coordination of the electron in their $\mathrm{N}$ or $\mathrm{C}$ atoms to metal ion or organic groups. These properties make them superior flexibility in the synthesis and modifications (Shafaatian et al. 2014). Thus, this work aims to give a new input to the synthesis of Schiff-base/SBA-15 nanoadsorbent with abundant hydroxyl groups by post-grafting procedure. Then, we explore its application for MB removal from aqueous solutions and discuss the mechanism of MB adsorption onto the functionalized nanoadsorbent. With respect to the obtained results, it can be concluded that our novel nanoadsorbent is better in comparison with other nanoadsorbents (Suraja et al. 2013; Dong et al. 2010) in terms of initial cost, fast kinetic, and quantitative removal of huge amount of $\mathrm{MB}$ in shorter times by small value of nanoadsorbent. These observations make Schiff-base/SBA-15 nanoadsorbent as a good candidate for MB removal toward other adsorbents. Furthermore, the precise control of conditions for the preparation of nanoadsorbent can be regarded as a disadvantage of the present study.

\section{Materials and methods}

Reagents and chemicals

Pluronic P123 (Aldrich EO20PO70EO20, EO ethylene oxide, $\mathrm{PO}$ propylene oxide, $\mathrm{MW}=5,800$ ), tetraethoxysilane (TEOS $98 \%$ GC Aldrich), salicylaldehyde, (3-aminopropyl) trimethoxysilane (APTMS), $\mathrm{HNO}_{3}$, and $\mathrm{HCl}$ were purchased from Sigma-Aldrich, Merck, and Acros organics companies. All of the other reagents and solvents were of analytical reagent grade and were used as received. Dabble distillated water was used in all experiments.

Measurements

The XRD patterns were recorded on a Bruker D8ADVANCE by using Ni-filtered $\mathrm{Cu} \mathrm{K}_{\mathrm{a}}$ radiation with a speed of $2 \mathrm{~min}^{-1}$ and a current of $1.5406 \mathrm{~A}$. $\mathrm{N}_{2}$ adsorption-desorption isotherms were obtained at $77.35 \mathrm{~K}$ using a Quantachrome Autosorb-1 apparatus. The specific surface-area was calculated using the Brunauer-EmmettTeller (BET) method, while the micropore volume was estimated by the t-plot method. The pore size distribution, the total pore volume, and mean pore diameter were derived using the Barrett-Joyner-Halenda (BJH) method. Thermo-gravimetric (TG) analysis was performed by heating the samples under $\mathrm{N}_{2}$ flow at a rate of $25 \mathrm{~mL} / \mathrm{min}$ using a TA instrument 2050 thermo-gravimetric analyzer with a heating rate of $20^{\circ} \mathrm{C} / \mathrm{min}$. The FT-IR spectra were recorded on a Jasco 4200 FT-IR spectrophotometer using $\mathrm{KBr}$ disks. The TEM images were obtained from a Philips CM10 electron microscope at $100 \mathrm{kV}$. The UV-Vis spectra were measured with a double-beam Shimadzu UV-Visible 1650 PC spectrophotometer equipped with $1.0 \mathrm{~cm}$ quartz cells.

SBA-15 and Schiff-base/SBA-15 nanoadsorbent synthesis

At first, SBA-15 was prepared according to Zhao's approach (Zhao et al. 1998). In a typical preparation, $4.0 \mathrm{~g}$ of P123 was dissolved in $30 \mathrm{~g}$ of deionized water and $120 \mathrm{~g}$ of $2 \mathrm{M}$ hydrochloric acid solution with stirring, and $8.50 \mathrm{~g}$ of TEOS was added later, while the solution was stirred. The reaction mixture was vigorously stirred at $35{ }^{\circ} \mathrm{C}$ for $20 \mathrm{~h}$ and then aged at $80^{\circ} \mathrm{C}$ for $12 \mathrm{~h}$ without stirring. The solid product was filtered, washed with deionized water, and air-dried at room temperature. The material was calcined to remove the template by slowly increasing temperature from room temperature to $550{ }^{\circ} \mathrm{C}$ in $8 \mathrm{~h}$ and heating at $550{ }^{\circ} \mathrm{C}$ for $6 \mathrm{~h}$. 
Schiff-base/SBA-15 nanoadsorbent was synthesized by adding salicylaldehyde $(0.12 \mathrm{~g}, 1 \mathrm{mmol})$ and APTMS $(0.18 \mathrm{~g}, 1 \mathrm{mmol})$ to absolute $\mathrm{MeOH}(5 \mathrm{~mL})$. After $3 \mathrm{~h}$ of the stirring solution at room temperature, SBA-15 (1.5 g) was added to the solution and the dispersion was stirred for $24 \mathrm{~h}$. Then, the solvent was removed using a rotary evaporator, and the resulting white solid was dried at $80{ }^{\circ} \mathrm{C}$ overnight. The solid product was filtered, washed thoroughly with deionized water, and dried at $80{ }^{\circ} \mathrm{C}$ for $8 \mathrm{~h}$ (Scheme 1).

\section{Adsorption experiments}

The adsorption of $\mathrm{MB}$ in aqueous solution on the asprepared Schiff-base/SBA-15 nanoadsorbent was performed in a batch experiment and conducted in duplicate. $0.002 \mathrm{~g}$ of the Schiff-base/SBA-15 nanoadsorbent was added into $10 \mathrm{~mL}$ of $\mathrm{MB}$ solutions of desired initial concentrations $(20-60 \mathrm{mg} / \mathrm{L})$ under agitation in a temperature-controlled shaker. At predetermined time intervals, the samples were removed from the solution by centrifugation. The effect of $\mathrm{pH}$ on the adsorption of $\mathrm{MB}$ on the Schiff-base/SBA-15 nanoadsorbent was studied over a $\mathrm{pH}$ range of 2.0-10.0 with a contact time of $65 \mathrm{~min}$. The $\mathrm{pH}$ was adjusted by adding aqueous solutions of $0.1 \mathrm{~mol} / \mathrm{L} \mathrm{HCl}$ or $0.1 \mathrm{~mol} / \mathrm{L} \mathrm{NaOH}$. The concentrations of $\mathrm{MB}$ solutions were analyzed by measuring their absorbance at $660 \mathrm{~nm}$ on a UV-Visible spectrophotometer. This wavelength corresponds to the maximum absorption peak of the MB dye. A calibration curve was obtained by using standard MB solutions of known concentrations versus the absorbance. The experimental data of calibration were fitted by a straight line with a high determination coefficient $\left(R^{2}=0.999\right)$. The amount of MB adsorbed per unit mass of the adsorbent and percent adsorption (\%) were evaluated by using the mass balance equation (Chala et al. 2014; Spires-Jones et al. 2014):

$q=\left(\left(C_{0}-C_{\mathrm{e}}\right) V\right) / m$

$\%$ adsorption $=\left(100 \times\left(C_{0}-C_{\mathrm{e}}\right)\right) / C_{0}$

where $q(\mathrm{mg} / \mathrm{g})$ is the amount of adsorbed dye per gram of adsorbent, $C_{0}$ and $C_{\mathrm{e}}$ are the initial and equilibrium concentrations of $\mathrm{MB}$ in the solution $(\mathrm{mg} / \mathrm{L})$, respectively, $\mathrm{m}$ is the mass of the adsorbent used $(\mathrm{g})$, and $V(\mathrm{~L})$ is the initial volume of the MB solution.

\section{Results and discussion}

\section{Characterization of Schiff-base/SBA-15 nanoadsorbent}

Figure 1a shows XRD patterns of pure SBA-15 and Schiff-base/SBA-15 nanoadsorbent. For the pure SBA15 , three resolved diffraction peaks are clearly observed

Scheme 1 Preparation of the Schiff-base/SBA-15 nanoadsorbent

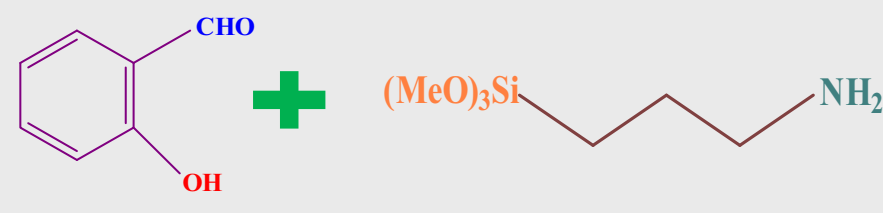

MeOH

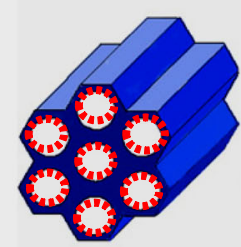

Schiff-base/SBA-15 nanoadsorbent

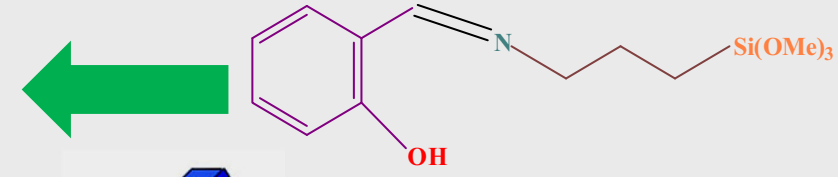

Schiff-base ligand

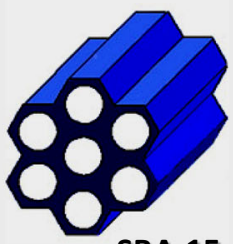



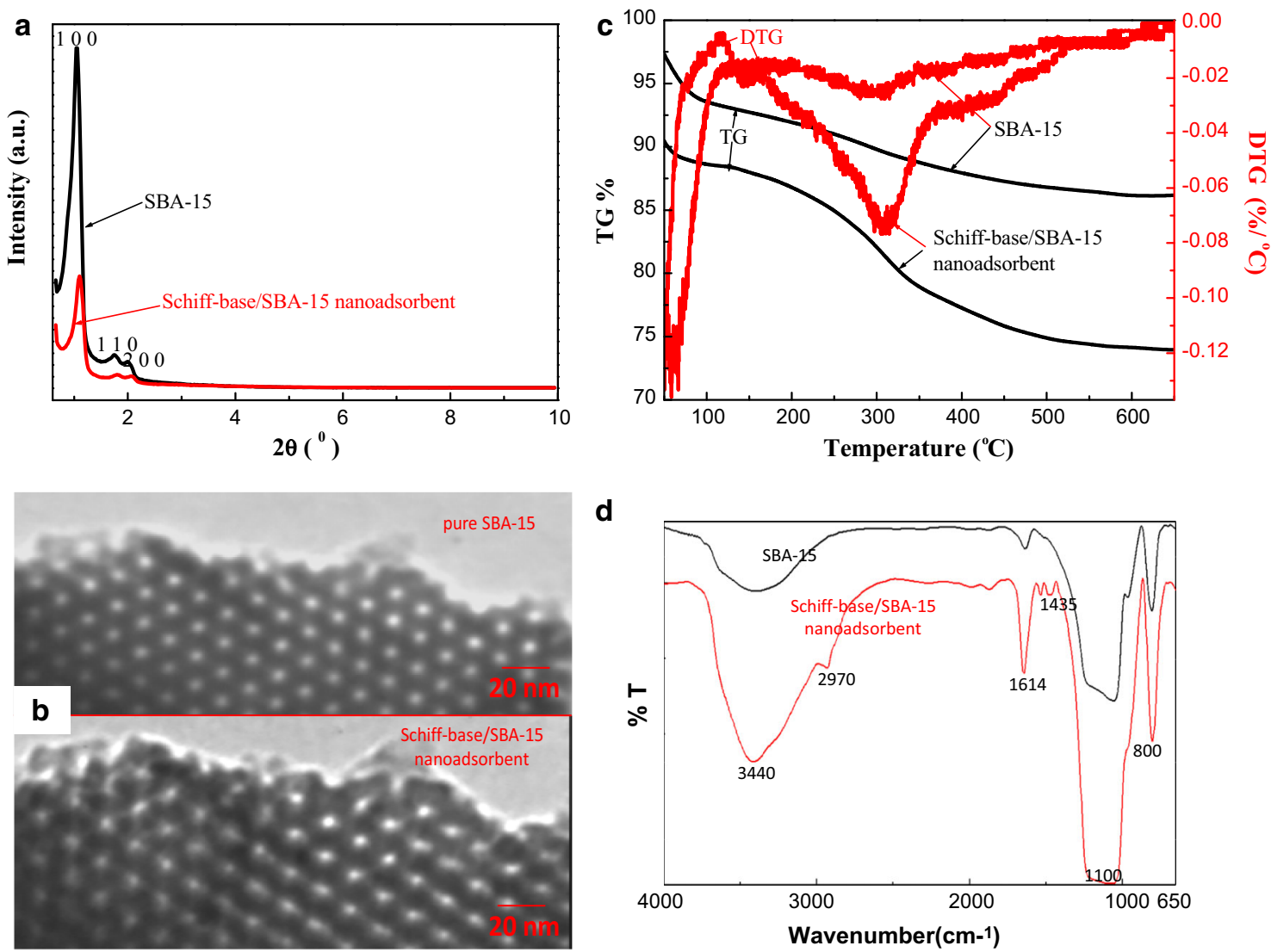

d
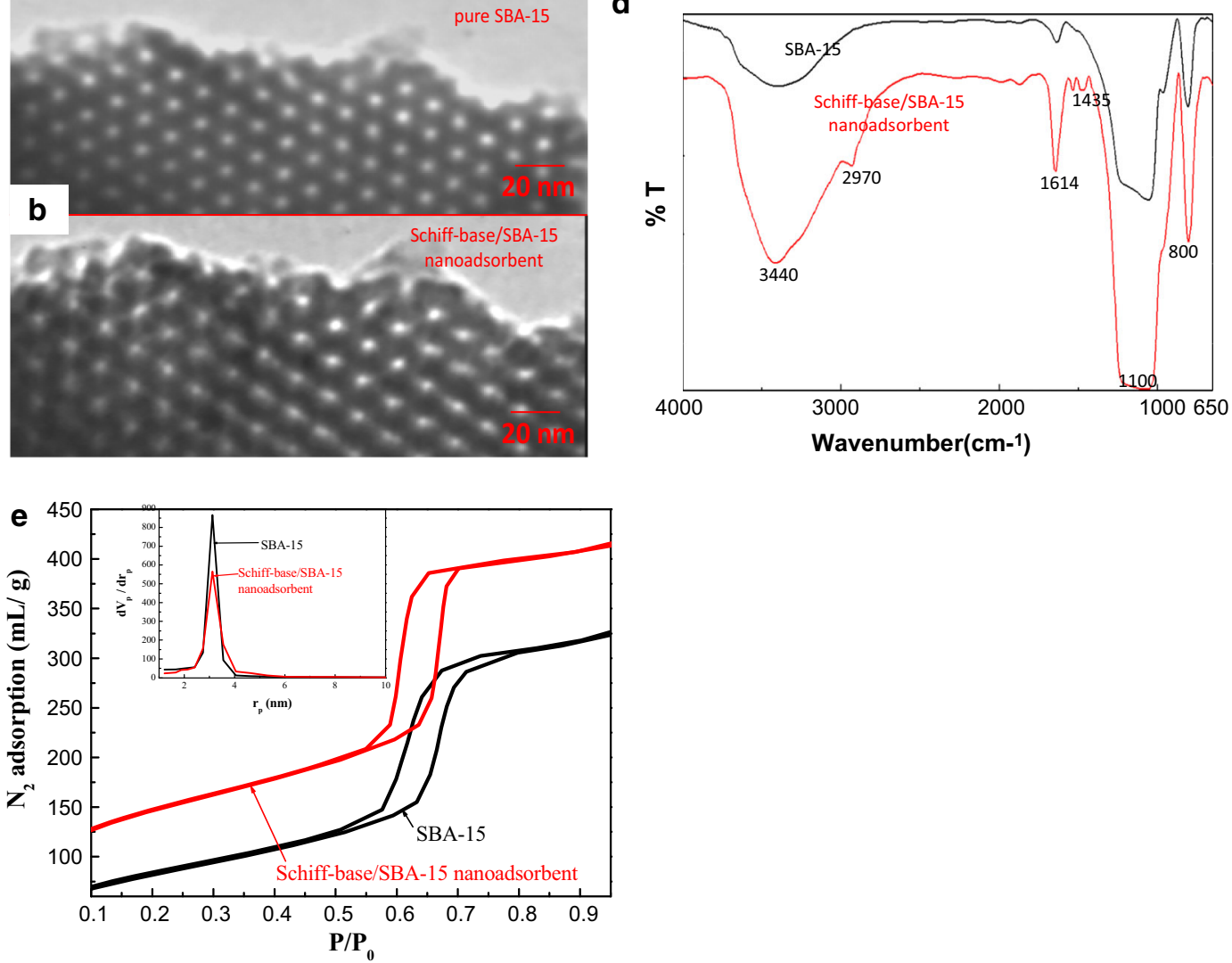

Fig. 1 a XRD patterns of the pure SBA-15 and Schiff-base/SBA-15 nanoadsorbent, b TEM images of the pure SBA-15 and Schiff-base/ SBA-15 nanoadsorbent, c TG/DTG curves of the pure SBA-15 and Schiff-base/SBA-15 nanoadsorbent, d FT-IR spectra of pure SBA-15

and Schiff-base/SBA-15 nanoadsorbent, e $\mathrm{N}_{2}$ adsorption-desorption isotherms with pore size distributions at inset of the pure SBA-15 and Schiff-base/SBA-15 nanoadsorbent

at $2 \theta$ values of $0.991,1.701$, and 1.961 , which are indexed as (100), (110), and (200) reflections. These peaks indicate an ordered hexagonal nanoporous materials with high symmetry (Cheraghali et al. 2013; Bardajee et al. 2013). The Schiff-base/SBA-15 nanoadsorbent has an intensive (100) reflection, indicating the

presence of ordered hexagonal structure similar to pure SBA-15. However, the peak intensity, especially for the (100), decreases significantly. This is probably due to the shrinking of the lattice as a result of condensation (Bardajee et al. 2013). TEM images of the pure SBA-15 and Schiff-base/SBA-15 nanoadsorbent are shown in 
Fig. 1b. Both images confirm the ordered channel structure of nanoporous SBA-15 and Schiff-base/SBA-15 nanoadsorbent which are in good agreement with XRD data (Cheraghali et al. 2013; Bardajee et al. 2013). The pore size of SBA-15 is about $3.3 \mathrm{~nm}$, but the pore size of Schiff-base/SBA-15 nanoadsorbent is about $1.5 \mathrm{~nm}$. It can be explained by the incorporation of Schiff-base moiety in the SBA-15 matrix during grafting process. Schiff-base/SBA-15 nanoadsorbent and pure SBA-15 were characterized by TG/DTG experiment. As shown in Fig. 1c, two important weight loss processes could be observed for these samples. The weight loss between 50 and $100{ }^{\circ} \mathrm{C}$ might be ascribed to the desorbed physisorbed water. The peak starting at $200{ }^{\circ} \mathrm{C}$ and centered at $309{ }^{\circ} \mathrm{C}$ could be attributed to the decomposition of organic templates. It could be found that the content of organic templates in the Schiff-base/SBA-15 nanoadsorbent significantly decreased by increasing the temperature, and the extracted material showed a residual template content around $73.0 \mathrm{wt} \%$ (Hernández-Morales et al. 2012). The FT-IR spectra of the pure SBA-15 and Schiff-base/SBA-15 nanoadsorbent are shown in Fig. 1d. As can be seen from Fig. 1d, the Schiff-base/SBA-15 nanoadsorbent shows bands associated with both the SBA-15 and the Schiff-base ligand. The broad band at around 1,435 and $3,440 \mathrm{~cm}^{-1}$ can be assigned to the hydroxyl stretching vibrations. The broad band at around $1,614 \mathrm{~cm}^{-1}$ is the characteristic of the $\mathrm{C}=\mathrm{N}$ stretching bands. In addition, the strong peak for stretching of $\mathrm{Si}-$ $\mathrm{O}-\mathrm{Si}$ and the bending vibration of $\mathrm{Si}-\mathrm{O}-\mathrm{Si}$ can be detected at 1,100 and $800 \mathrm{~cm}^{-1}$, respectively (Bardajee et al. 2013). The $\mathrm{N}_{2}$ adsorption-desorption isotherms of the pure SBA-15 and Schiff-base/SBA-15 nanoadsorbent are shown in Fig. 1e. The type IV IUPAC isotherms' characteristic of capillary condensation in nanopores was observed for these samples. The sharpness of the hysteresis indicates the uniformity of nanopores for the both samples. However, their shapes are different, with a capillary condensation of $\mathrm{N}_{2}$ occurring over a slightly lower $\mathrm{P} / \mathrm{P}_{0}$ range when going from SBA-15 to Schiffbase/SBA-15 nanoadsorbent (Yan et al. 2013; Da'na and Sayari 2011). The distribution of pore size measured by the BJH method on the materials is also shown in Fig. 1e. It can be seen that the nanoporous diameter decreases with the same order for the adsorbed $\mathrm{N}_{2}$ volume. The physicochemical properties of the materials (Table 1) were calculated from the data of the isotherms with the correlation coefficient from BET fitting. The reduction in the specific surface area and pore size of Schiff-base/ SBA-15 nanoadsorbent to SBA-15 can be due to the presence of Schiff-base, which blocks the channels.
Table 1 Physicochemical properties of pure SBA-15 and Schiffbase/SBA-15 nanoadsorbent

\begin{tabular}{llll}
\hline Sample & $\begin{array}{l}\text { Surface area } \\
\left(\mathrm{m}^{2} / \mathrm{g}\right)\end{array}$ & $\begin{array}{l}\text { Pore volume } \\
\left(\mathrm{cm}^{3} / \mathrm{g}\right)\end{array}$ & $\begin{array}{l}\text { Pore } \\
\text { diameter } \\
(\mathrm{nm})\end{array}$ \\
\hline $\begin{array}{l}\text { Pure SBA-15 } \\
\begin{array}{l}\text { Schiff-base/SBA-15 } \\
\text { nanoadsorbent }\end{array}\end{array}$ & 397.24 & 0.6004 & 3.12 \\
\hline
\end{tabular}

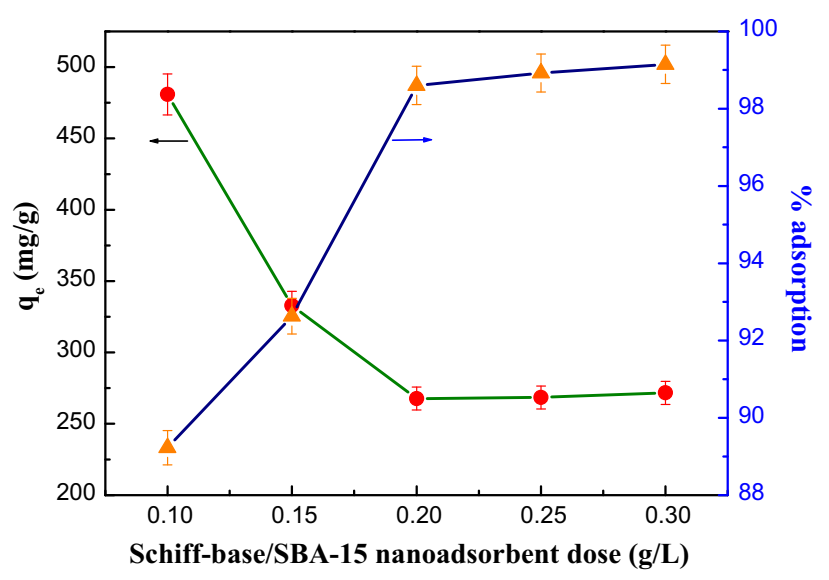

Fig. 2 Effect of Schiff-base/SBA-15 nanoadsorbent dose on the adsorption of MB. Conditions: initial MB concentration, $50 \mathrm{mg} / \mathrm{L}$; temperature, $25{ }^{\circ} \mathrm{C} ; \mathrm{pH}, 8$; contact time, $65 \mathrm{~min}$

\section{Adsorption of MB onto Schiff-base/SBA-15} nanoadsorbent

\section{Effect of Schiff-base/SBA-15 nanoadsorbent dose}

The $q_{\mathrm{e}}$ and $\%$ adsorption of $\mathrm{MB}$ at different doses of Schiff-base/SBA-15 nanoadsorbent are shown in Fig. 2. It was observed that the \% adsorption of MB increased from 89.22 to $99.14 \%$ when the adsorbent load increased from 0.1 to $0.3 \mathrm{~g} / \mathrm{L}$. On the other hand, the plot of $q_{\mathrm{e}}$ versus adsorbent dose reveals that with increasing Schiff-base/ SBA-15 nanoadsorbent dosage from 0.1 to $0.3 \mathrm{~g} / \mathrm{L}$, the values of $q_{\mathrm{e}}$ decreased from 480.89 to $241.68 \mathrm{mg} / \mathrm{g}$. The primary factor explaining this characteristic is that adsorption sites remain unsaturated during the adsorption reaction, whereas the number of sites available for adsorption site increases by increasing the adsorbent dose. At higher Schiff-base/SBA-15 nanoadsorbent concentration, there is a very fast superficial adsorption onto the Schiff-base/SBA-15 nanoadsorbent surface that produces a lower solute concentration in the solution than when Schiff-base/SBA-15 nanoadsorbent dose is lower. Thus, 


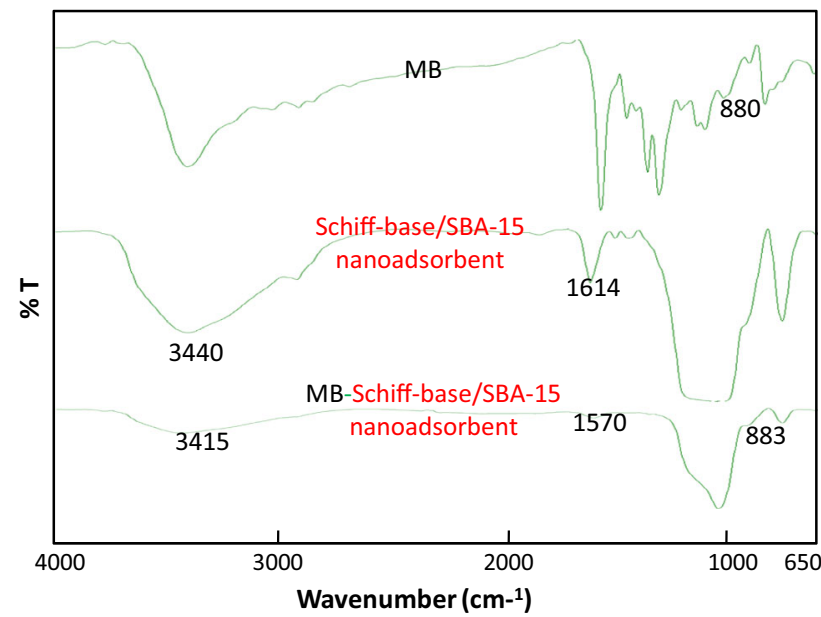

Fig. 3 FT-IR spectra of MB, Schiff-base/SBA-15 nanoadsorbent, and MB-loaded Schiff-base/SBA-15 nanoadsorbent

with increasing adsorbent dose, the amount of MB adsorbed per unit mass of Schiff-base/SBA-15 nanoadsorbent reduced, thus causing a decrease in $\mathrm{q}_{\mathrm{e}}$ value (Messina and Schulz 2006). To confirm the adsorption of MB onto Schiff-base/SBA-15 nanoadsorbent, the FT-IR spectra (Fig. 3) of MB, Schiff-base/SBA-15 nanoadsorbent, and MB-loaded Schiff-base/SBA-15 nanoadsorbent were studied. After the adsorption processes, the FT-IR spectrum of Schiff-base/SBA-15 nanoadsorbent shows some characteristic peaks of MB. The adsorption band of Schiff-base/ SBA-15 nanoadsorbent at $1,614 \mathrm{~cm}^{-1}$ corresponds to $\mathrm{C}=\mathrm{N}$ shift to $1,570 \mathrm{~cm}^{-1}$, indicating that $\mathrm{C}=\mathrm{N}$ of Schiff-base/ SBA-15 nanoadsorbent plays an important role in the adsorption process. It also can be seen that the adsorption peaks at 3,440 $\mathrm{cm}^{-1}$ relating to $\mathrm{OH}$ of Schiff-base/SBA-15 nanoadsorbent shifts to wavenumbers $3,415 \mathrm{~cm}^{-1}$ which suggests that hydrogen bond could be involved in MB adsorption. Additionally, the characteristic adsorption peak of $\mathrm{MB}$ at $880 \mathrm{~cm}^{-1}$ ascribed to the aromatic rings appears at $883 \mathrm{~cm}^{-1}$ due to its interaction with nanoadsorbent.

\section{Effect of $\mathrm{pH}$ on adsorption}

The effects of initial solution $\mathrm{pH}$ on the adsorption of $\mathrm{MB}$ onto Schiff-base/SBA-15 nanoadsorbent were investigated at $\mathrm{pH} 2-10,25^{\circ} \mathrm{C}$, and an initial $\mathrm{MB}$ concentration of $50 \mathrm{mg} / \mathrm{L}$. As shown in Fig. 4 and Scheme 2, adsorption of MB on Schiff-base/SBA-15 nanoadsorbent in the $\mathrm{pH}$ values below 4 is lower than basic solutions. At lower $\mathrm{pH}$ values, the dimethylamine groups in MB molecule are protonated (the $\mathrm{pK}_{\mathrm{a}}$ value of $\mathrm{MB}$ molecule is 3.8). Moreover, at low $\mathrm{pH}$, the surface of adsorbents would be

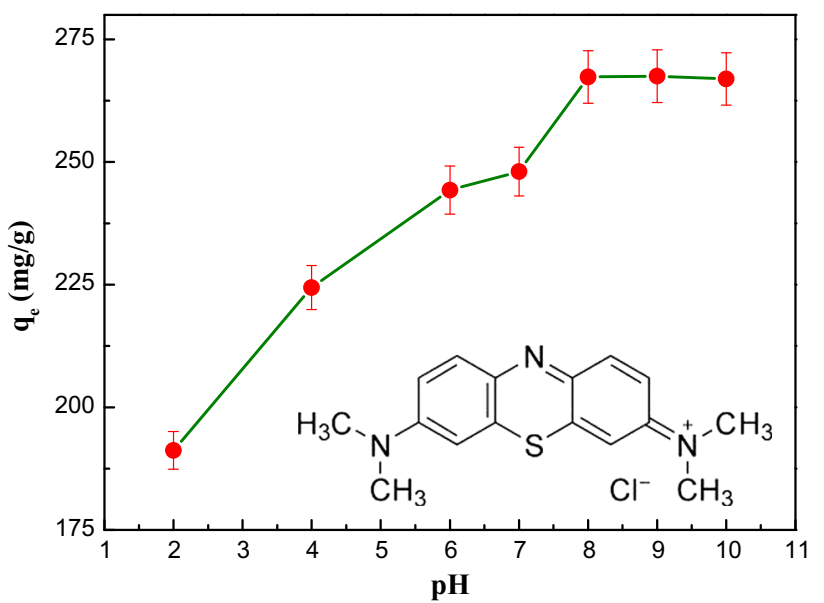

Fig. 4 Effect of pH on the adsorption of MB by Schiff-base/SBA-15 nanoadsorbent. Conditions: initial $\mathrm{MB}$ concentration, $50 \mathrm{mg} / \mathrm{L}$; temperature, $25{ }^{\circ} \mathrm{C}$; adsorbents, $0.2 \mathrm{mg} / \mathrm{L}$; contact time, $65 \mathrm{~min}$

surrounded by the hydrogen ions which compete with MB ions for interaction with the sites of the sorbent. Overall, the protonation of dimethylamine groups in MB molecules along with the protonation of the surface of adsorbent causes a weak sorption for the MB. In other words, by increasing the $\mathrm{pH}$ of the medium, deprotonating of $\mathrm{MB}$ as well as adsorbent functional groups for the creation of active centers can simultaneously occur. The molecule interactions between MB and Schiff-base/SBA-15 nanoadsorbent during the adsorption process are schematically represented in Scheme 2. In higher $\mathrm{pH}$, both the hydrogen bonding and electrostatic interactions cause an efficient removal of MB from wastewater samples (Bui and Choi 2009).

Different adsorption of MB regarding the initial solution $\mathrm{pH}$ can also be described on the basis of the structure of $\mathrm{MB}$ molecule and adsorbent point of zero charge $\left(\mathrm{pH}_{\mathrm{ZPC}}\right)$. At $\mathrm{pH}<4$, the surface of Schiff-base/SBA-15 nanoadsorbent may obtain positive charge (due to $\mathrm{H}_{3} \mathrm{O}^{+}$ions presence) that lead to electrostatic repulsion between the MB molecules and positive charge of active Schiff-base/SBA15 nanoadsorbent. On the contrary at $\mathrm{pH}>4$, the surface of Schiff-base/SBA-15 nanoadsorbent may attain negative charge leading to an increase in MB uptake due to the electrostatic attraction force.

\section{Effect of initial MB concentration on adsorption}

Figure 5 shows the adsorption of different concentration of MB onto Schiff-base/SBA-15 nanoadsorbent as a function of contact time at $25{ }^{\circ} \mathrm{C}$. Adsorption studies were carried 


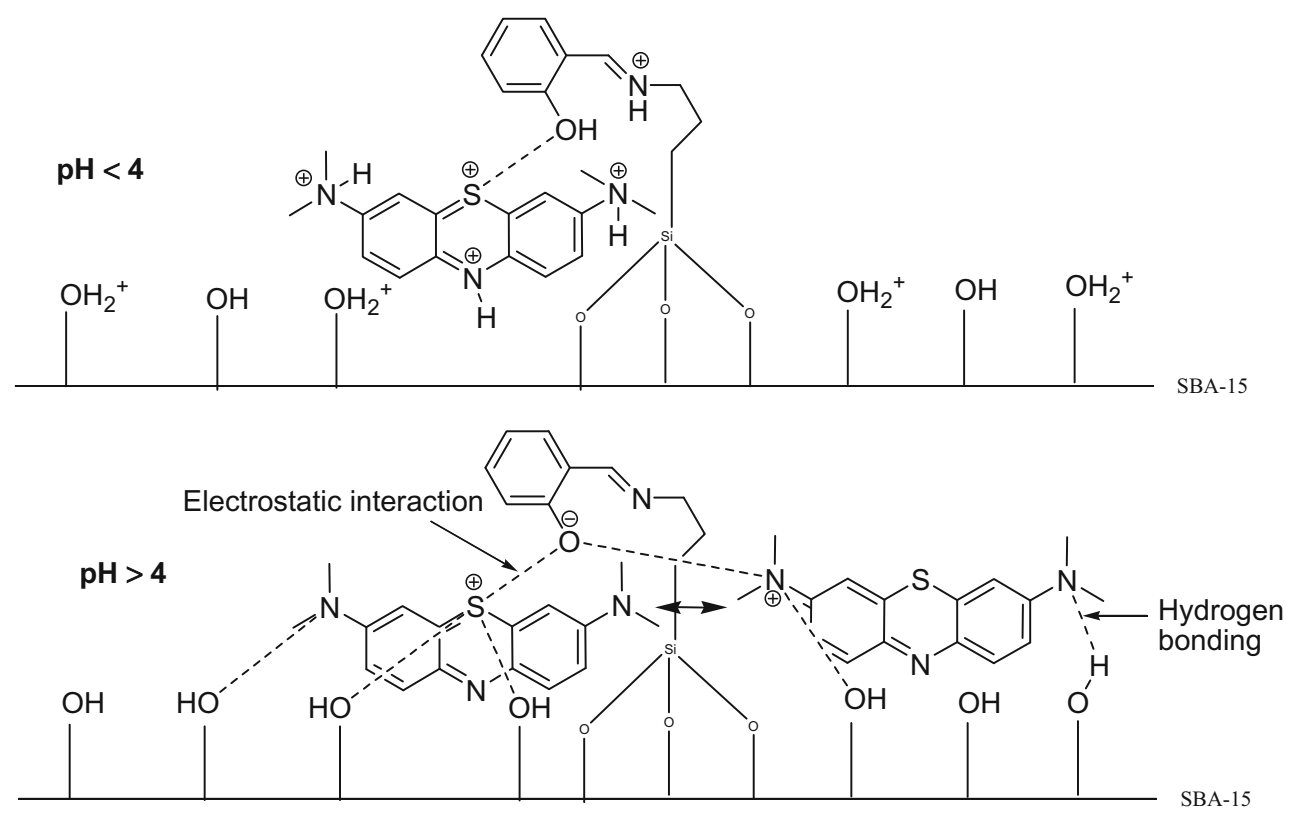

Scheme 2 A plausible mechanism for the MB adsorption on the Schiff-base/SBA-15 nanoadsorbent

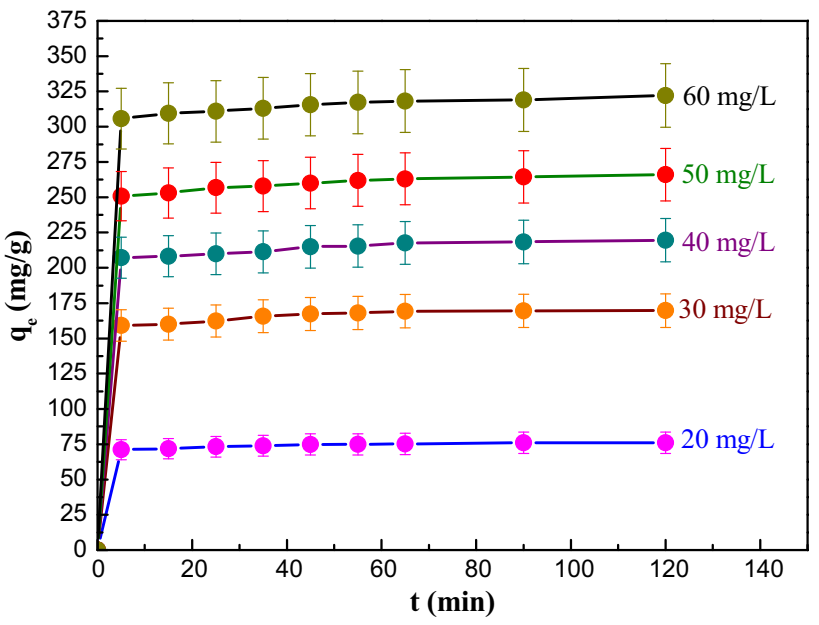

Fig. 5 Effect of initial concentration on MB adsorption by Schiffbase/SBA-15 nanoadsorbent. Conditions: initial MB concentration, $50 \mathrm{mg} / \mathrm{L}$; temperature, $25^{\circ} \mathrm{C}$; adsorbents, $0.2 \mathrm{mg} / \mathrm{L} ; \mathrm{pH}, 8$

out for $2 \mathrm{~h}$, and it was observed that the amount of adsorbed MB increased linearly with time at the beginning of adsorption. It is clear from Fig. 5 that a larger amount of MB was removed in the first 5 min of contact time and the equilibrium was established in $65 \mathrm{~min}$ for all studied absorbents. The amount of dye adsorbed at the equilibrium time reflects the maximum adsorption capacity of the adsorbent under those operating conditions. The $\mathrm{q}_{\mathrm{e}}$ increased with an increase in the initial $\mathrm{MB}$ concentrations from 20 to $60 \mathrm{mg} / \mathrm{L}$, because the initial concentration provided an important driving force to overcome all mass transfer resistance (Messina and Schulz 2006).

\section{Adsorption isotherm models}

It is important to analyze the adsorption isotherms for design purposes. Therefore, experimental data were analyzed with Langmuir isotherm and Freundlich isotherm, the well-known adsorption isotherm models. Nonlinear equation of Langmuir and Freundlich isotherms are expressed as the following, respectively (Langmuir 1918; Freundlich 1906):

$q_{\mathrm{e}}=\left(q_{\mathrm{m}} K_{\mathrm{L}} C_{\mathrm{e}}\right) /\left(1+K_{\mathrm{L}} C_{\mathrm{e}}\right)$

$q_{\mathrm{e}}=K_{\mathrm{f}} C_{\mathrm{e}}^{1 / n}$

where $q_{\mathrm{m}}(\mathrm{mg} / \mathrm{g})$ is the maximum adsorption capacity corresponding to complete monolayer coverage. $C_{\mathrm{e}}(\mathrm{mg} / \mathrm{L})$ and $q_{\mathrm{e}}(\mathrm{mg} / \mathrm{g})$ are the concentration of $\mathrm{MB}$ in the solution and the adsorption capacity at the equilibrium, respectively. $K_{\mathrm{L}}$ is adsorption equilibrium constant $(\mathrm{Lm} / \mathrm{g}) . K_{\mathrm{f}}$ and $1 / \mathrm{n}$ are the Freundlich constants; $K_{\mathrm{f}}$ represents the relative adsorption capacity of the adsorbent, and $\mathrm{n}$ represents the degree of dependence of adsorption on the equilibrium concentration of MB. The Langmuir and 


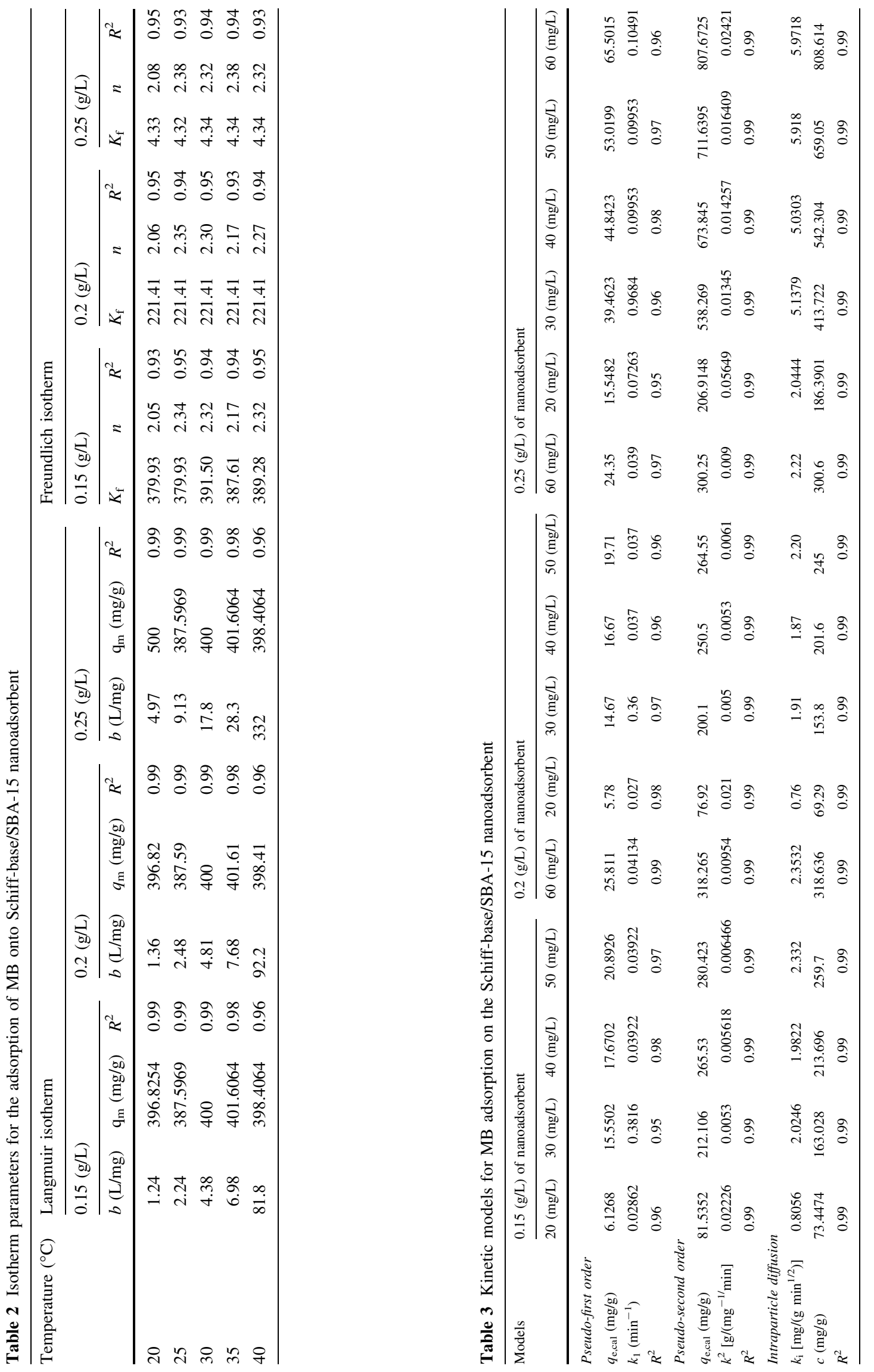


Freundlich constants were calculated and are summarized in Table 2. The data for the adsorption of MB onto the Schiff-base/SBA-15 nanoadsorbent were well fitted by the Langmuir isotherm model at all temperatures, as demonstrated by the high correlation coefficients $\left(R^{2}\right)$ compared to that of the Freundlich isotherm. This might be due to the monolayer adsorption of MB onto the Schiff-base/SBA-15 nanoadsorbent (Cheraghali et al. 2013). It is obvious that Schiff-base/SBA-15 nanoadsorbent has relatively high value of adsorption capacity (396.82 $\mathrm{mg} / \mathrm{g}$ ) using $0.15 \mathrm{~g} / \mathrm{L}$ of nanoadsorbent.

\section{Kinetic models}

Kinetic models have been proposed for determining the mechanism of interaction. The mechanism of adsorption depends on the physical and/or chemical characteristics of the adsorbent as well as on the mass transport process. In order to determine the adsorption mechanism of MB onto Schiff-base/SBA-15 nanoadsorbent, pseudo-first- and pseudo-second-order kinetic models have been proposed as follows to elucidate that the mechanism of adsorption depends on the characteristics of the adsorbent. These two models can be expressed in linear form as Eqs. (5) and (6), respectively (Bui and Choi 2009; Wang et al. 2013).

$\ln \left(q_{\mathrm{e}}-q_{t}\right)=\ln q_{\mathrm{e}}-k_{1} t$

$t / q_{t}=1 /\left(k_{2} q_{\mathrm{e}}^{2}\right)+t / q_{\mathrm{e}}$

where $q_{\mathrm{e}}$ and $q_{\mathrm{t}}(\mathrm{mg} / \mathrm{g})$ are the amounts of adsorbed MB at equilibrium and at time $\mathrm{t}$, respectively. $k_{1}\left(\mathrm{~min}^{-1}\right)$ and $k_{2}$ $(\mathrm{g} / \mathrm{mg} / \mathrm{min})$ are the pseudo-first-order and pseudo-secondorder model rate constant, respectively. The values of the $k_{1}, k_{2}$, calculated $q_{\mathrm{e}, \mathrm{cal}}$ and the correlation coefficient of these two models are listed in Table 3. The data show an excellent fit to pseudo-second-order model with high $R^{2}$ (0.999). A good fit can be further confirmed by the fact that the calculated $q_{\mathrm{e}}$ value is very close to the measured one. Therefore, MB adsorption on the Schiff-base/SBA-15 nanoadsorbent is able to explain experimental data at most conditions according to the pseudo-second-order kinetic model (Hernández-Morales et al. 2012).

Weber's intraparticle diffusion model is used to further identify the steps of adsorption process. It can be expressed as Eq. (7) as follows (Li et al. 2014).

$q_{t}=k_{\mathrm{i}} t^{1 / 2}+c$

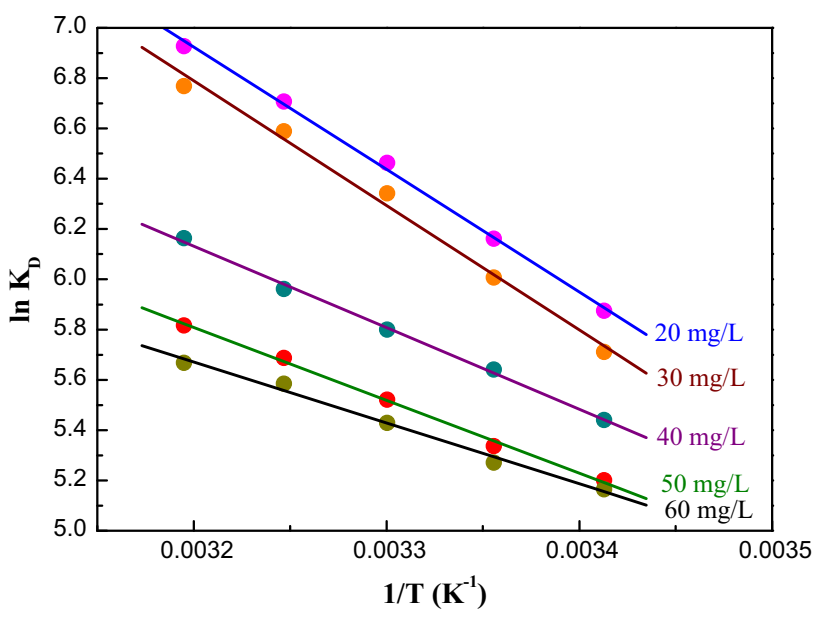

Fig. 6 Plot of $\ln K_{D}$ versus $1 / T$ for the MB adsorption on the Schiffbase/SBA-15 nanoadsorbent

where $q_{t}(\mathrm{mg} / \mathrm{L})$ is the adsorption capacity at time $t(\mathrm{~min})$; $k_{\mathrm{i}}\left(\mathrm{mg} /\left(\mathrm{g} \mathrm{min}^{1 / 2}\right)\right)$ is the rate constant of intraparticle diffusion; $I$ is a constant associated with thickness of the boundary layer. As shown in Table 3 , the $R^{2}$ values (0.99) demonstrate good applicability of Weber's intraparticle diffusion model in studying of MB adsorption onto the Schiff-base/SBA-15 nanoadsorbent.

\section{Thermodynamic analysis}

The inherent energetic changes related to the adsorption process can be reflected by thermodynamic parameters, such as free energy change $\left(\Delta G^{\circ}, \mathrm{kJ} / \mathrm{mol}\right)$, entropy change $\left(\Delta S^{\circ}, \mathrm{J} / \mathrm{mol} / \mathrm{K}^{1}\right)$, and enthalpy change $\left(\Delta \mathrm{H}^{\circ}, \mathrm{kJ} / \mathrm{mol}\right)$. They can be determined using the following equations (Hernández-Morales et al. 2012):

$\Delta G^{\circ}=-R T \ln \left(K_{\mathrm{D}}\right)$

$\ln \left(K_{\mathrm{D}}\right)=\Delta S^{\circ} / R-\Delta H^{\circ} / R T$

where $R$ and $T$ represent the universal gas constant $(8.314 \mathrm{~J} / \mathrm{K} / \mathrm{mol})$ and the system temperature $(K)$, respectively. $K_{\mathrm{D}}$ is distribution coefficient calculated from the experiment data using equation below (Wang et al. 2013):

$$
\begin{aligned}
K_{\mathrm{D}}= & (\text { Equilibrium concentration of MB adsorbed on Schiff-base } / \\
& \text { SBA-15 nanoadsorbent }) /(\text { Equilibrium concentration of } \\
& \text { MB in solution })=\left(\left(C_{0}-C_{\mathrm{e}}\right) V\right) /\left(C_{\mathrm{e}} m\right)
\end{aligned}
$$


Table 4 Thermodynamic parameters for the MB adsorption on the Schiff-base/SBA-15 nanoadsorbent

\begin{tabular}{|c|c|c|c|c|c|c|c|}
\hline \multirow{2}{*}{$\begin{array}{l}\text { Concentration } \\
\text { of } \mathrm{MB}(\mathrm{mg} / \mathrm{L})\end{array}$} & \multirow[t]{2}{*}{$\Delta H^{\circ}(\mathrm{kJ} / \mathrm{mol})$} & \multirow[t]{2}{*}{$\Delta S^{\circ}(\mathrm{J} / \mathrm{mol} \mathrm{K})$} & \multicolumn{5}{|c|}{$\Delta G^{\circ}(\mathrm{kJ} / \mathrm{mol})$} \\
\hline & & & 293 & 298 & 303 & 308 & 313 \\
\hline 20 & 41.19 & 188.23 & -14.33 & -15.27 & -16.20 & -17.13 & -18.10 \\
\hline 30 & 40.48 & 187.10 & -13.96 & -14.90 & -15.84 & -16.78 & -17.72 \\
\hline 40 & 26.94 & 137.18 & -13.25 & -13.93 & -14.62 & -15.31 & -15.99 \\
\hline 50 & 24.12 & 125.46 & -12.64 & -13.27 & -13.90 & -14.52 & -15.15 \\
\hline 60 & 20.31 & 111.58 & -12.56 & -13.12 & -13.68 & -14.23 & -14.79 \\
\hline
\end{tabular}

$\Delta G^{\circ}$ can be easily determined from Eq. (8). $\Delta S^{\circ}$ and $\Delta H^{\circ}$ are determined from the intercept and slope of the van't Hoff plots of $\ln \left(K_{\mathrm{D}}\right)$ versus $1 / \mathrm{T}$ (Fig. 6). The values of $\Delta G^{\circ}, \Delta H^{\circ}$, and $\Delta S^{\circ}$ are listed in Table 4 . The negative $\Delta G^{\circ}$ values of $\mathrm{MB}$ at various temperatures are due to the fact that the adsorption processes are spontaneous with a high preference of MB on Schiff-base/SBA-15 nanoadsorbent and the negative value of $\Delta G^{\circ}$ increased with an increase in temperature, indicating that the spontaneous nature of adsorption of $\mathrm{MB}$ is proportional to the temperature. The positive value of $\Delta H^{\circ}$ confirms the endothermic character of adsorption of MB on Schiff-base/SBA-15 nanoadsorbent, and the positive value of $\Delta S^{\circ}$ confirmed the increased randomness at solid/solution interface during the adsorption process (Anbia and Amirmahmoodi 2011; Da'na and Sayari 2011).

\section{Conclusion}

In this study, the novel Schiff-base/SBA-15 nanoadsorbent was successfully prepared by a post-grafting procedure and was characterized by XRD, TEM, FT-IR, TG, and $\mathrm{N}_{2}$ adsorption/desorption isotherms. Adsorption ability of the as-obtained Schiff-base/SBA-15 nanoadsorbent is evaluated by choosing $\mathrm{MB}$ as a model dye. Batch adsorption tests demonstrate that the adsorption is affected by various conditions. The equilibrium data were best described by the Langmuir isotherm model. The kinetic data were well described by the pseudo-second-order kinetic model, which suggested that the process was controlled by chemisorption. The thermodynamic parameters indicated that the adsorption of MB on Schiff-base/SBA-15 nanoadsorbent was an endothermic and spontaneous process.
Acknowledgments Authors are thankful to the Payame Noor University for the funding of this study (with grant number of 62370).

\section{References}

Adam F, Appaturi JN, Khanam Z, Thankappan R, Nawi MAM (2013) Utilization of tin and titanium incorporated rice husk silica nanocomposite as photocatalyst and adsorbent for the removal of methylene blue in aqueous medium. Appl Surf Sci 264:718-726

Ahmed MJ, Theydan SK (2014) Optimization of microwave preparation conditions for activated carbon from Albizia lebbeck seed pods for methylene blue dye adsorption. J Anal Appl Pyrolysis 105:199-208

Anacona JR, Rodriguez JL, Camus J (2014) Synthesis, characterization and antibacterial activity of a Schiff base derived from cephalexin and sulphathiazole and its transition metal complexes. Spectrochim Acta Mol Biomol 129:96-102

Anbia M, Amirmahmoodi S (2011) Adsorption of phenolic compounds from aqueous solutions using functionalized SBA-15 as a nano-sorbent. Sci Iran 18:446-452

Bardajee GR, Malakooti R, Abtin I, Atashin H (2013) Palladium Schiff-base complex loaded SBA-15 as a novel nanocatalyst for the synthesis of 2,3-disubstituted quinoxalines and pyridopyrazine derivatives. Microporous Mesoporous Mat 169:67-74

Bui TX, Choi H (2009) Adsorptive removal of selected pharmaceuticals by mesoporous silica SBA-15. J Hazard Mater 168:602-608

Chala S, Wetchakun K, Phanichphant S, Inceesungvorn B, Wetchakun N (2014) Enhanced visible-light-response photocatalytic degradation of methylene blue on Fe-loaded $\mathrm{BiVO}_{4}$ photocatalyst. J Alloys Compd 597:129-135

Chang W, Deka JR, Wu H, Shieh F, Huang S, Kao H (2013) Synthesis and characterization of large pore cubic mesoporous silicas functionalized with high contents of carboxylic acid groups and their use as adsorbents. Appl Catal B 142-143:817-827

Cheraghali R, Tavakoli H, Sepehrian H (2013) Preparation, characterization and lead sorption performance of alginate-SBA-15 composite as a novel adsorbent. Sci Iran 20:1028-1034

Chunhui Y, Guohui B, Hong Y, Xiaopu X, Zherong B, Mingyuan W, Xinsheng Z, Juanjuan W, Changqing L, Wuping L (2013) Quantitative evaluation of plasma after methylene blue and 
white light treatment in four Chinese blood centers. Transfus Apher Sci 49:631-639

Da'na E, Sayari A (2011) Optimization of copper removal efficiency by adsorption on amine-modified SBA-15: experimental design methodology. Chem Eng J 167:91-98

Dong Y, Lu B, Zang S, Zhao J, Wang X, Cai Q (2010) Removal of methylene blue from coloured effluents by adsorption onto SBA15. J Chem Technol Biotechnol 86:616-619

Freundlich HMF (1906) Over the adsorption in solution. J Phys Chem $57: 385-470$

Ghaedi M, Pakniat M, Mahmoudi Z, Hajati S, Sahraei R, Daneshfar A (2014a) Synthesis of nickel sulfide nanoparticles loaded on activated carbon as a novel adsorbent for the competitive removal of methylene blue and safranin-O. Spectrochim Acta Mol Biomol 5:402-409

Ghaedi M, Zeinali N, Ghaedi AM, Teimuori M, Tashkhourian J (2014b) Artificial neural network-genetic algorithm based optimization for the adsorption of methylene blue and brilliant green from aqueous solution by graphite oxide nanoparticle. Spectrochim Acta Mol Biomol 125:264-277

Ghaedi M, Ansari A, Habibi MH, Asghari AR (2014c) Removal of malachite green from aqueous solution by zinc oxide nanoparticle loaded on activated carbon: kinetics and isotherm study. J Ind Eng Chem 20:17-28

Guo J, Li B, Liu L, Lv K (2014) Removal of methylene blue from aqueous solutions by chemically modified bamboo. Chemosphere 111:225-231

Hernández-Morales V, Nava R, Acosta-Silva YJ, Macías-Sánchez SA, Pérez-Bueno JJ, Pawelec B (2012) Adsorption of lead (II) on SBA-15 mesoporous molecular sieve functionalized with $-\mathrm{NH}_{2}$ groups. Microporous Mesoporous Mater 160:133-142

Karimi H, Ghaedi M (2014) Application of artificial neural network and genetic algorithm to modeling and optimization of removal of methylene blue using activated carbon. J Ind Eng Chem 20:2471-2476

Langmuir I (1918) The adsorption of gases on plane surfaces of glass, mica and platinum. J Am Chem Soc 40:1361-1403

Li Q, Yu H, Song J, Pan X, Liu J, Wang Y, Tang L (2014) Synthesis of SBA-15/polyaniline mesoporous composite for removal of resorcinol from aqueous solution. Appl Surf Sci 290:260-266

Lin $\mathrm{C}$, Wu Y, Luo F, Chen D, Chen X (2014) A label-free electrochemical DNA sensor using methylene blue as redox indicator based on an exonuclease III-aided target recycling strategy. Biosens Bioelectron 59:365-369

Liu Y, Kang Y, Mu B, Wang A (2014) Attapulgite/bentonite interactions for methylene blue adsorption characteristics from aqueous solution. Chem Eng J 237:403-410
Messina PV, Schulz PC (2006) Adsorption of reactive dyes on titania-silica mesoporous materials. J Colloid Interface Sci 299:305-320

Petzer A, Harvey BH, Petzer JP (2014) The interactions of azure B, a metabolite of methylene blue, with acetylcholinesterase and butyrylcholinesterase. Toxicol Appl Pharmacol 274:488-493

Rafatullah M, Sulaiman O, Hashim R, Ahmad A (2010) Adsorption of methylene blue on low-cost adsorbents: a review. J Hazard Mater 177:70-80

Shafaatian B, Soleymanpour A, Oskouei NK, Notash B, Rezvani SA (2014) Synthesis, crystal structure, fluorescence and electrochemical studies of a new tridentate Schiff base ligand and its nickel (II) and palladium (II) complexes. Spectrochim Acta Mol Biomol 128:363-369

Spires-Jones TL, Friedman T, Pitstick R, Polydoro M, Roe A, Carlson GA, Hyman BT (2014) Methylene blue does not reverse existing neurofibrillary tangle pathology in the $\mathrm{rTg} 4510$ mouse model of tauopathy. Neurosci Lett 562:63-68

Suchithra PS, Vazhayal L, Mohamed AP, Ananthakumar S (2012) Mesoporous organic-inorganic hybrid aerogels through ultrasonic assisted sol-gel intercalation of silica-PEG in bentonite for effective removal of dyes, volatile organic pollutants and petroleum products from aqueous solution. Chem Eng J 200-202:589-600

Suraja PV, Yaakob Z, Binitha NN, Triwahyono S, Silija PP (2013) Co3O4 doped over SBA 15: excellent adsorbent materials for the removal of methylene blue dye pollutant. Clean Technol Environ Policy 15:967-972

Suresh R, Giribabu K, Manigandan R, Munusamy S, Kumar SP, Muthamizh S, Stephen A, Narayanan V (2014) Doping of Co into $\mathrm{V}_{2} \mathrm{O}_{5}$ nanoparticles enhances photodegradation of methylene blue. J Alloys Compd 598:151-160

Tang C, Zheng P, Chen T, Zhang J, Mahmood Q, Ding S, Chen X, Chen J, Wu D (2011) Enhanced nitrogen removal from pharmaceutical wastewater using SBA-ANAMMOX process. Water Res 45:201-210

Ting H, Chen C, Lu F, Suen S (2014) Adsorption and photodegradation of methylene blue using a bulk Ti material with porous titania layer prepared by chemical oxidation. J Taiwan Inst Chem Eng 45:617-624

Valle-Vigón P, Sevilla M, Fuertes AB (2013) Carboxyl-functionalized mesoporous silica-carbon composites as highly efficient adsorbents in liquid phase. Microporous Mesoporous Mater 176:78-85

Wang X, Zhu G, Guo F (2013) Removal of uranium (VI) ion from aqueous solution by SBA-15. Ann Nucl Energy 56:151-157

Wang Y, Zhang X, He X, Zhang W, Zhang X, Lu C (2014) In situ synthesis of $\mathrm{MnO}_{2}$ coated cellulose nanofibers hybrid for 
effective removal of methylene blue. Carbohydr Polym 110:302-308

Yan H, Lu P, Pan Z, Wang X, Zhang Q, Li L (2013) Ce/SBA-15 as a heterogeneous ozonation catalyst for efficient mineralization of dimethyl phthalate. J Mol Catal A Chem 377:57-64
Zhao D, Feng J, Huo Q, Melosh N, Fredrickson GH, Chmelka B, Stucky GD (1998) Triblock copolymer syntheses of mesoporous silica with periodic 50 to 300 angstrom pores. Science 279:548-552 